\title{
Loss of Catheter Lock Fluid Is Caused by Hydraulic Effects and Not by Diffusion
}

\author{
Hans-Dietrich Polaschegg
}

Kösterberg, Austria

Sir,

the recent paper by Zhang et al. [1] about the use of antibiotic catheter locks makes the assumption that filling the catheter with an 'amount of locking solution exactly equally to one lumen of the catheter' avoids spillage of the lock solution into the blood stream. Nevertheless, gentamicin concentrations were elevated prior to next dialysis and this was attributed to the 'diffusion of very small amounts of gentamicin from the locking solution'.

I disagree with both statements. When a matching volume of locking solution is instilled as described approximately $25 \%$ is spilled instantly into the blood stream [2]. Subsequently the region between the catheter tip and the most distal side hole is rinsed out which is followed by an exchange of lock solution with plasma or whole blood if the lock density is higher (in case of jugular catheters) compared to plasma or whole blood, respectively [3].

Diffusion is an extremely slow process as shown already by Graham [4]. In the interdialytic interval of 2-3 days diffusion only contributes a negligible amount to spillage [5].
Although the above-cited measurements were done in vitro, the results are applicable in vivo because the processes are based on simple laws of physics. They are also corroborated by clinical observations. Increased aPTT has been reported when samples were taken shortly after locking [6-8].

The low gentamicin concentration measured by Zhang et al. prior to the next treatment does not reflect the gentamicin load immediately after locking. It may be the result of the elimination process in the interdialytic interval.

Spillage of fluid locks cannot be avoided. This must be taken into account when a potential hazardous substance is used for locking.

\section{References}

1 Zhang P, Yuan J, Tan H, Lv R, Chen J: Successful prevention of cuffed hemodialysis catheter-related infection using an antibiotic lock technique by strictly catheter-restricted antibiotic lock solution method. Blood Purif 2009;27:206-211.
2 Polaschegg HD: Catheter locking solution spillage: theory and experimental verification. Blood Purif 2008;26:255-260.

-3 Polaschegg HD: Loss of catheter locking solution caused by fluid density. ASAIO J 2005; 51:230-235.

4 Graham T: X. Liquid diffusion applied to analysis. Philos Trans R Soc Lond 1861;151: 183-224.

5 Polaschegg HD: Diffusion study. Hemodial Int 2004;8:304-305.

-6 Sombolos KI, Fragia TK, Bamichas GI, Christidou FP, Stangou MI, Karagianni AC, Natse TA, Georgoulis IE: Heparin solution locked in acute hemodialysis catheters: impact on activated partial thromboplastin time. ASAIO J 2003;49:287-289.

-7 Karaaslan H, Peyronnet P, Benevent D, Lagarde $\mathrm{C}$, Rince $\mathrm{M}$, Leroux-Robert C: Risk of heparin lock-related bleeding when using indwelling venous catheter in haemodialysis. Nephrol Dial Transplant 2001;16:20722074

-8 Pepper RJ, Gale DP, Wajed J, Bommayya G, Ashby D, McLean A, Laffan M, Maxwell PH: Inadvertent postdialysis anticoagulation due to heparin line locks. Hemodial Int 2007; 11:430-434.

\section{KARGER}

Fax +4161306 1234 E-Mail karger@karger.ch www.karger.com
Dr. Hans-Dietrich Polaschegg Malenweg 12

AT-9231 Köstenberg (Austria)

Tel. +43 42744045 , E-Mail hdp@aon.at 